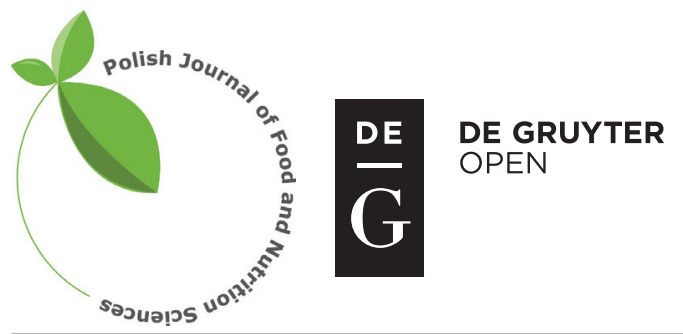

Pol. J. Food Nutr. Sci., 2016, Vol. 66, No. 2, pp. 109-117

DOI: $10.1515 /$ pjfns-2016-0001 http://journal.pan.olsztyn.pl

Review article

Section: Nutritional Research

\title{
Blood Glucose Lowering Efficacy of Strawberry Extracts Rich in Ellagitannins with Different Degree of Polymerization in Rats
}

\author{
Jerzy Juśkiewicz ${ }^{1 *}$, Adam Jurgonski ${ }^{1}$, Krzysztof Kołodziejczyk², Monika Kosmala ${ }^{2}$, \\ Joanna Milala ${ }^{2}$,Zenon Zdunczyk ${ }^{1}$, Bartosz Fotschki ${ }^{1}$, Ewa Żary-Sikorska ${ }^{3}$ \\ ${ }^{1}$ Institute of Animal Reproduction and Food Research of the Polish Academy of Sciences, \\ Division of Food Science, Tuwima 10, 10-748 Olsztyn, Poland \\ 2Institute of Food Technology and Analysis, Eódź University of Technology, Stefanowskiego 4/10, 90-924 Eódź, Poland \\ ${ }^{3}$ University of Science and Technology, Bernardyńska 6/8, Bydgoszcz, Poland
}

Key words: strawberry, ellagitannins, degree of polymerization, postprandial glycaemia, rat

In two experiments on rats it was analyzed whether the lowering rate of postprandial glycaemia depends on the degree of polymerization of strawberry ellagitannins (ET). Two types of highly-concentrated polyphenolic extracts were used, one rich in monomeric ET (ETM; $94.9 \%$ polyphenols and 67\% ETM in it), the second in dimeric ET (ETD; 95.9\% polyphenols, and 78.0\% ETD in it). The experiment 1 comprised three oral sugar tolerance tests, GTT (with glucose; to examine monosaccharide transport across epithelium), SuTT (with sucrose; to examine the activity of mucosal disaccharidase) and StTT (with starch; to examine the action of salivary alpha-amylase, and then of pancreatic amylase in the small intestine as well as all the aforementioned mechanisms), while in the experiment 2 the healthy and pre-diabetic rats were subjected to 1-h small intestine perfusion with fluids containing glucose or sucrose. Considering the shape of blood glucose concentration curve following GTT and SuTT, as well as changes in glycaemia and mucosal disaccharidases activity observed within and after small intestine perfusion, the ETM (vs. ETD) extract more positively mitigated sugar-induced postprandial glycaemic load. Contrary to expectations, the effect of extracts on pre-diabetic rats was negligible. The extract ETD, in turn, potently mitigated starch-induced postprandial glycaemic load during test StTT. The results clearly showed that the separate mechanisms (glucose transport across the intestine, intestinal mucosal disaccharidases inhibition activity, pancreatic $\alpha$-amylase inhibitory activity) leading to decreased postprandial glycaemia upon dietary administration of strawberry ellagitannins largely depended on their chemical structure, i.e. degree of polymerization.

\section{INTRODUCTION}

It is well known that fasting and postprandial blood glucose concentrations are regulated by different mechanisms. The former one, quite opposite to the latter, is only minimally affected by the amount and rate of sugar absorption while eating [Saris et al., 1998]. The most recognized dietary component that influenced postprandial blood glucose level are digestible carbohydrates: monosaccharides (e.g. glucose, fructose), disaccharides (e.g. sucrose) and polysaccharides (e.g. starch). The metabolic fate of different sugars, the involvement of several physiological mechanisms in the digestion processes, their impact on blood glucose level, and effects of other ingested together dietary components could be effectively investigated with the use of oral tolerance tests, i.e. glucose tolerance test GTT, sucrose tolerance test SuTT, and starch tolerance test StTT [Jurgoński et al., 2015]. In this case, the action of dietary polyphenols is likely to be multiple, and includes the inhibition of carbohydrates digestion

\footnotetext{
* Corresponding Author: E-mail: j.juskiewicz@pan.olsztyn.pl (Prof. Jerzy Juśkiewicz)
}

and monosaccharide transport across the intestinal wall, improving insulin secretion and its sensitivity, modification of hepatic glucose release, and many others [Williamson, 2013]. Ellagitannins (ET) - high contents of which may be found in fruits of plants of the family Rosaceae (strawberries, raspberries and blackberries) - are high-molecular esters of a monosaccharide (usually $\beta$-D-glucose) and a few residues of hexahydroxydiphenic acid. They are characterized by a complex structure that has not been entirely explored. In general and due to their large molecular size, ET are not absorbed but reach the distal part of the gastrointestinal tract where they are metabolized by microbiota [Espin et al., 2007; Fotschki et al., 2014]. These results may indicate that ET could exert some biological effects in the gut while their metabolites (e.g. urolithins) could be responsible for systemic effects [Kosmala et al., 2015].

To our best knowledge, there are no reports as for biological response of animals or humans to consumed ET that differ in degree of polymerization. A similar idea laid behind an earlier research conducted in our lab, but it concerned physiological response of experimental birds to very small difference in the length of dietary carbohydrate chain [Juskiewicz et al., 2008a]. The results from that study clearly showed that dif- 
ferent physiological effects might follow even small changes in the chemical structure of dietary components. The present research analyzed whether the lowering rate of blood glucose levels depends on the degree of polymerization of strawberry ET given to rats in the form of high-concentrated polyphenolic extracts in oral sugar tolerance tests as well as with the aid of the perfusion technique of the small intestine. Because it is well known that dietary polyphenolic compounds may affect minerals bioavailability [Juśkiewicz et al., 2009], in the latter case the absorption rate of selected minerals $(\mathrm{Mg}, \mathrm{P}, \mathrm{Ca})$ from the small intestine was also examined. The hypothesis of this study is that strawberry monomeric and dimeric ellagitannins differently affect the mechanisms comprising carbohydrates digestion as well as monosaccharide and selected minerals transport across the intestinal wall. The dosage of polyphenols used in the present study, $20 \mathrm{mg} / \mathrm{kg}$ of BW, may reflect a consumption of $0.5 \mathrm{~kg}$ fresh strawberries with average concentration of polyphenols by an adult weighing $70 \mathrm{~kg}$.

\section{MATERIAL AND METHODS}

\section{Production of strawberry extracts rich in ellagitannins}

The extracts were obtained from strawberry fruit pomace, a by-product of the manufacture of concentrated strawberry juice (ALPEX Co., Łęczeszyce, Poland), as described by Juśkiewicz et al. [2015]. Briefly, the fresh pomace was dried in an industrial vacuum dryer at $70 \pm 2{ }^{\circ} \mathrm{C}$ and then passed through sieves. The seedless fraction was subjected to a two-stage extraction with a $60 \%$ aqueous solution of acetone. Next, after partial removal of the solvent via distillation, the resultant solutions were transferred onto a column packed with polymeric resin (Amberlite XAD 16, SigmaAldrich). The sugars and other water-soluble compounds present in the solutions were eluted from the column with water. Then, monomeric and dimeric ET-rich fractions were desorbed with $10 \%$ and $40 \%$ aqueous solution of ethanol, respectively, concentrated to $c a$. $15 \%$ of dry matter and lyophilized. The methods used to determine the composition of the monomeric ET (ETM)- and dimeric ET (ETD)-rich extracts (details in Table 1) are described below.

\section{Chemical analyses of strawberry extracts}

The basic chemical composition of the extracts was determined according to the official methods of AOAC [2005] using the following procedures: 940.26 (dry substance and ash), 920.152 (protein), 930.09 (crude fat), and 985.29 (total dietary fiber). Contents of free ellagic acid (EA), sum of ellagitannins and other polyphenols were determined with the HPLC method in solutions of ellagitannin preparations with the concentration of 1 to $5 \mathrm{mg} / \mathrm{mL}$ of methanol solution.

Chromatographic analysis was conducted with a chromatograph by KNAUER Smartline (Berlin, Germany) equipped in degasser, two pumps, mixer, autosampler, thermostat and PDA detector. Separation was carried out on a Phenomenex Gemini 5u C18 110A 250×4.60 mm column; $5 \mu \mathrm{m}$ (Phenomenex, Torrance, CA, USA). The column was thermostated at $35^{\circ} \mathrm{C}$. Phase A was $0.05 \%$ phosphoric acid in water, and phase $\mathrm{B}$ was $0.05 \%$ phosphoric acid in $80 \%$ acetonitrile.
TABLE 1. Chemical composition of strawberry ellagitannins (ET) extracts $(\mathrm{g} / 100 \mathrm{~g})^{1}$.

\begin{tabular}{lcc}
\hline & $\begin{array}{c}\text { Monomeric } \\
\text { ET-rich extract }\end{array}$ & $\begin{array}{c}\text { Dimeric } \\
\text { ET-rich extract }\end{array}$ \\
\hline Dry matter & 95.9 & 98.4 \\
Ash & 0.03 & 1.54 \\
Fat & 0.03 & 0.06 \\
Protein & 0.80 & 0.70 \\
Other components ${ }^{2}$ & 0.10 & 0.20 \\
Total polyphenols & 94.9 & 95.9 \\
Ellagic acid & 0.0 & 0.0 \\
Ellagitannins & 67.0 & 84.7 \\
Monomers & 67.0 & 6.70 \\
Dimers & 0.0 & 78.0 \\
Proanthocyanidins & 27.0 & 11.0 \\
Anthocyanins & 0.0 & 0.0 \\
Flavonols & 0.90 & 0.20 \\
\hline
\end{tabular}

${ }^{1}$ The analyses were made in duplicate; ${ }^{2}$ Low-molecular carbohydrates and structural components of plant cell walls extracted from fruit pomace and calculated from the difference between dry matter and determined components; ${ }^{3}$ Flavonols $=$ quercetin and kaempferol with their glycosides .

The flow rate of the liquid phase was $1.25 \mathrm{~mL} / \mathrm{min}$. Separation was conducted in the following gradient system: $0-5 \mathrm{~min}$ $4 \% \mathrm{~B} ; 5-12.5 \min 4-15 \% \mathrm{~B} ; 12.5-42.5 \min 15-40 \% \mathrm{~B} ; 42.5$ - $51.8 \min 40-50 \%$ B; $51.8-53.4 \min 50-55 \%$ B; and $53.4-$ $55 \mathrm{~min} 4 \% \mathrm{~B}$. Volume of the injected sample was: $20 \mu \mathrm{L}$. Conditions of detection were as follows: $280 \mathrm{~nm}$ ( $p$-coumaric acid, kaempferol-3-O- $\beta$-D-(6"-E-p-coumaroyl)-glucopyranoside), $360 \mathrm{~nm}$ (ellagic acid, quercetin and kaempferol glycosides, quercetin, kaempferol), and $520 \mathrm{~nm}$ (anthocyanins). Data were registered using ClarityChrom software for data collection and processing (Knauer, Berlin, Germany). Polyphenols were identified using the following standards: ellagic acid, quercetin-3-O-glucoside, kaempferol-3-O-glucoside, quercetin, kaempferol, pelargonidin-3-O-glucoside, kaempferol-3-O- $\beta$-D-(6"-E-p-coumaroyl)-glucopyranoside (KpCG, tiliroside) (Extrasynthese, Genay, France), and $p$-coumaric acid (Sigma-Aldrich, Steinheim, Germany) and the standards of agrimoniin (dimer) and bis-hydroxy-HHDP (monomers) obtained as described by Sójka et al. [2013].

Proanthocyanidins degradation method in an acidic environment with an overdose of phloroglucinol was used. The method was described by Kennedy \& Jones [2001]. About $20 \mathrm{mg}$ of a sample was weighed to a $2 \mathrm{~mL}$ Eppendorf tube, and then, $800 \mu \mathrm{L}$ of a methanol solution containing phloroglucinol $(75 \mathrm{~g} / \mathrm{L})$ and ascorbic acid $(15 \mathrm{~g} / \mathrm{L})$ was added to the sample. Phloroglucinolysis was started by adding $400 \mu \mathrm{L}$ of $0.2 \mathrm{~mol} / \mathrm{L}$ hydrochloric acid in methanol. The incubation was carried out for $30 \mathrm{~min}$ at the temperature of $50^{\circ} \mathrm{C}$. Next, the samples were instantly cooled down in an ice bath, and the reaction was stopped by adding $600 \mu \mathrm{L}$ of a $40 \mathrm{mmol} / \mathrm{L}$ sodium acetate solution. The samples 
were centrifuged for $5 \mathrm{~min}$ at $3600 \times g$ and then diluted with a $40 \mathrm{mmol} / \mathrm{L}$ sodium acetate solution. Products of acidic degradation of proanthocyanidins were separated with the Knauer Smartline chromatograph (Berlin, Germany) equipped with a UV-Vis P2800 detector (Knauer, Berlin, Germany) and a fluorescent detector (FD) RF-10AXL (Schimadzu, Tokyo, Japan). The separation was conducted on Gemini $5 \mathrm{u}$ C18 110A $250 \mathrm{~mm} 94.6 \mathrm{~mm}, 5 \mu \mathrm{m}$ column with gradient elution with $2.5 \%$ water solution (v/v) of acetic acid (phase A) and $80 \%(\mathrm{v} / \mathrm{v})$ acetonitrile in water (phase B). The following gradient was used: 0-10 min, 4-7\% B; 10-27 min, 7-30\% B; 27-29 $\mathrm{min}, 30-70 \% \mathrm{~B} ; 29-34 \mathrm{~min}, 70 \% \mathrm{~B} ; 34-35 \mathrm{~min}, 70$ $4 \% \mathrm{~B}$; and $35-40 \mathrm{~min}, 4 \% \mathrm{~B}$. The flow rate was $1 \mathrm{~mL} / \mathrm{min}$, the temperature was $25^{\circ} \mathrm{C}$ and the volume of injection was $20 \mu \mathrm{L}$. The identification of components was conducted on the basis of comparing the retention times and UV-Vis spectra of standards of (-)-epicatechin, (+)-catechin, (-)-epigallocatechin, adducts: (-)-epigallocatechin-phloroglucinol, (-)-epicatechin-phloroglucinol and (+)-catechin-phloroglucinol. Quantitative analyses of released flavanols, i.e. $(+)$-catechin and (-)-epicatechin, were conducted on the basis of chromatograms recorded with the FD detector set at $278 \mathrm{~nm}$ excitation wavelength and $360 \mathrm{~nm}$ emission wavelength. Phloroglucinol adducts were determined on the basis of chromatograms registered with the PDA detector set at $280 \mathrm{~nm}$ wavelength.

\section{In vivo experiments}

Two main experiments were conducted, the first on 40 and the second on 72 adult male Wistar rats. The animal protocol used in this study was approved by the Institutional Animal Care and Use Committee in Olsztyn, Poland. The first experiment comprised three oral tolerance tests, i.e. glucose, sucrose and starch ones (GTT, SuTT and StTT, respectively). Forty adult male Wistar rats were fasted overnight, and 50\% glucose solution was gavaged intragastrically to each animal ( $2 \mathrm{~g} / \mathrm{kg}$ body weight; GTT test). Blood was then collected from the tail tip, and glucose concentration was measured using a glucometer Accu-Chek Go (Roche Diagnostics, Germany) at the following time intervals: 0, $15,30,60,90,120$, and $180 \mathrm{~min}$. The total area-under-thecurve (AUC) for 180 min was also calculated using the trapezoidal rule [Jurgoński et al., 2015]. After a 10-day break, the same rats were used in the next tests with $50 \%$ sucrose, and then with $40 \%$ soluble starch solutions (SuTT and StTT tests, respectively). The animals were subjected to the following treatments without or with extracts given intragastrically 5 min before the sugar load (each group, $n=10$ rats): the $\mathrm{C}$ negative group was given distilled water, the A positive group was given an acarbose solution $(35 \mathrm{mg} / \mathrm{kg} \mathrm{BW}$; group A), the ETM and ETD groups with extract solutions rich in monomeric or dimeric ET, respectively (each $20 \mathrm{mg}$ of polyphenols $/ \mathrm{kg} \mathrm{BW).} \mathrm{The} \mathrm{solution} \mathrm{concentrations} \mathrm{were} \mathrm{so}$ prepared that the amount equaled $1 \mathrm{~mL}$ per $350 \mathrm{~g}$ of BW, whereas group $\mathrm{C}$ received water in the same way. Acarbose is an $\alpha$-glucosidase inhibitor widely used in the treatment of diabetes, which delays the absorption of carbohydrates from the small intestine. In between tests, the animals had free access to tap water and a regular rodent chow, whereas during tests rats had free access to drinking water. All ani- mals were maintained in wired cages under a 12-hr light/dark cycle, a controlled temperature of $19^{\circ} \mathrm{C}$ to $22^{\circ} \mathrm{C}$ and intensive room ventilation (15 times per $h$ ).

In the second experiment, 72 adult male rats in a fasted state weighing about $308 \pm 11 \mathrm{~g}$ were used ( 8 rats in each group). The first stage of experiment II was conducted on 28 rats divided into 3 groups, control, ETM and ETD, and their intestine was perfused with a glucose-containing fluid $(2 \mathrm{~g} / \mathrm{L})$. In the second stage of experiment II with a sucrose-containing fluid $(2 \mathrm{~g} / \mathrm{L}), 48$ rats were used and divided into 6 groups of healthy and prediabetic animals: $\mathrm{C}, \mathrm{C}+\mathrm{STZ}$, ETM, ETM+STZ, ETD, ETD+STZ. The prediabetic state, in the groups marked with STZ, was induced three days before the perfusion study by a single intraperitoneal injection of $20 \mathrm{mg} / \mathrm{kg}$ BW of streptozotocin (STZ, Sigma, Poznań, Poland) freshly dissolved in $0.05 \mathrm{~mol} / \mathrm{L}$ sodium citrate buffer ( $\mathrm{pH} 4.5$ ). In the experimental groups given ETM and ETD extracts, the amount of polyphenols provided within 1-h perfusion was $20 \mathrm{mg}$ per rat (group ETM $351 \mathrm{mg}$ of ETM extract per $1 \mathrm{~L}$ of perfusion fluid; group ETD $347 \mathrm{mg} / \mathrm{L}$ ). Rats were anaesthetized by means of an intraperitoneal injection of sodium pentobarbital and body temperature was maintained at $37^{\circ} \mathrm{C}$ with an electric heating pad. The technique of the small intestine perfusion, precisely described in the work by Zduńczyk et al. [1998], was used to determine the absorption of glucose (stage 1) and minerals (stage 1 and 2) from the small intestine of rats receiving perfusion fluid without or with the addition of strawberry ETM and ETD extracts. Krebs-Henseleit fluid [Juśkiewicz et al., 2009], supplemented with proper amount of glucose or sucrose to level off its concentration in each group, was used as the control perfusion fluid. Following tracheotomy and laparotomy, two catheters were inserted in the small intestine, with the inlet immediately below duodenum and the outlet above the caecum. Perfusion fluids at a temperature of $37^{\circ} \mathrm{C}$ were administered for 60 mins into this limited section of the small intestine, following washing with a physiological saline solution $(0.9 \%$ $\mathrm{NaCl}$ ) and 20-min introductory period. Regular administration $(1 \mathrm{~mL} / \mathrm{min})$, close to a physiological rate, was ensured by a peristaltic pump PA-SK 8 (IKA-Labortechnik, Janke \& Kunkel, Germany). Anaesthesia was maintained by administration of intraperitoneal pentobarbital throughout the experimental period. Within the perfusion period, blood was collected from the tail tip, and glucose concentration was measured using a glucometer Accu-Chek Go (Roche Diagnostics, Germany) at the following time intervals: $0,15,30$, and $60 \mathrm{~min}$. The total area-under-the-curve (AUC) for $60 \mathrm{~min}$ was also calculated using the trapezoidal rule [Jurgoński et al., 2015]. The amount of compounds (glucose, calcium, magnesium and phosphorus) absorbed from the intestine was determined on the basis of differences in the composition of fluid given through the inlet drain and flowing out through the outlet drain. At the termination of the perfusion period, blood samples were taken from the inferior vena cava into test tubes, and then serum was obtained after solidification for $90 \mathrm{~min}$ at $37^{\circ} \mathrm{C}$ and centrifugation at $2000 \times g$ for $15 \mathrm{~min}$ at $4^{\circ} \mathrm{C}$. The concentrations of glucose, calcium, magnesium and phosphorus in the serum as well as perfusion fluids were determined with commercial diagnostic kits (Alpha Diagnos- 
tics Ltd., Warsaw, Poland). Immediately after blood taking, small intestine was removed and mucosa from the second quarter of the small intestine was collected by scraping with glass slides on an iced glass plate. After homogenization with four parts of a cold physiological saline $(\mathrm{v} / \mathrm{w})$ and centrifugation for $10 \mathrm{~min}\left(10,000 \times g, 4^{\circ} \mathrm{C}\right)$, the obtained supernatant was stored at $-20^{\circ} \mathrm{C}$ until analysis. The mucosal disaccharidase activity (sucrase, maltase, and lactase) was assayed using a procedure described by Jurgoński et al. [2013]. An aliquot of mucosal homogenate $(0.1 \mathrm{~mL})$ was incubated at $37^{\circ} \mathrm{C}$ with $0.1 \mathrm{~mL}$ of a substrate solution $(0.056 \mathrm{~mol} / \mathrm{L} \mathrm{su}-$ crose, maltose, or lactose in $0.2 \mathrm{~mol} / \mathrm{L}$ phosphate buffer, $\mathrm{pH}$ 7.0). After $30 \mathrm{~min}$ of incubation, $0.8 \mathrm{~mL}$ of cold distilled water was added, and the enzymatic reaction was interrupted by the immersion of the test tube in boiling water for $2 \mathrm{~min}$. In addition, a blank with the same composition was prepared and immersed in boiling water without prior incubation at $37^{\circ} \mathrm{C}$. The released glucose was determined using a glucose oxidase reagent (Alpha Diagnostic Ltd., Warsaw, Poland). The disaccharidase activity was expressed as $\mu \mathrm{mol}$ of glucose liberated from the respective disaccharide per min per $g$ of protein. The mucosal protein content was estimated using the Bradford method, with bovine serum albumin as the standard.

\section{Statistical analysis}

The Statistica software (StatSoft Corp., Kraków, Poland) was utilized to determine whether the variables differed among treatment groups. As for the tolerance oral tests GTT, SuTT and StTT, as well as for the perfusion experiment with healthy rats (stage 1 of the experiment II), the statistical analysis was performed using a one-way analysis of variance and the Duncan's multiple range post hoc test. The data were checked to be normally distributed and the variances were homogenous. In the second stage of experiment II, two-way repeated measures analysis of variance was performed with the type of extract applied (no addition, ETM or ETD) and health status (without and with STZ injection) of animals as two main factors, and their interaction $(\mathrm{E} \times \mathrm{STZ})$. If the analysis revealed a significant interaction effect, the differences between individual groups were analyzed with the Duncan's multiple range post hoc test $(P<0.05)$.

\section{RESULTS}

\section{Experiment 1}

The effect of the ETM extract on glycaemia in the GTT (glucose) test was more pronounced in comparison to the ETD one (Figure 1). The treatment with ETD was characterized by a significantly reduced glycaemia after 15, 30 and $180 \mathrm{~min}$ after glucose ingestion, as compared to the control rats. As for the ETM group, significantly decreased glycaemia levels were observed at 30, 90, 120 and 180 mins measuring points $(P<0.05$ vs. C). After 60 min of the GTT with extract ETM, a statistically significant trend towards lower blood glucose level was also noted $(\mathrm{P}=0.055 \mathrm{vs}$. $\mathrm{C})$. As a result of the above-mentioned changes in the GTT graph, the AUC value was significantly decreased by the ETM treatment only, as compared to the $\mathrm{C}$ animals.

There was a significant hypoglycaemic effect of acarbose treatment at all measuring points in the SuTT (sucrose) graph (Figure 2), which it was reflected in the AUC value $(P<0.001$; $975.6 \mathrm{mmol} / \mathrm{L}^{*} 180 \mathrm{~min} v s .1241 .5$ in group C). In comparison to the $\mathrm{C}$ group, the ETM extract effectively reduced glycaemia level in the SuTT test 15 and 30 min after sucrose ingestion, while the ETD extract was effective as hypoglycaemic agent

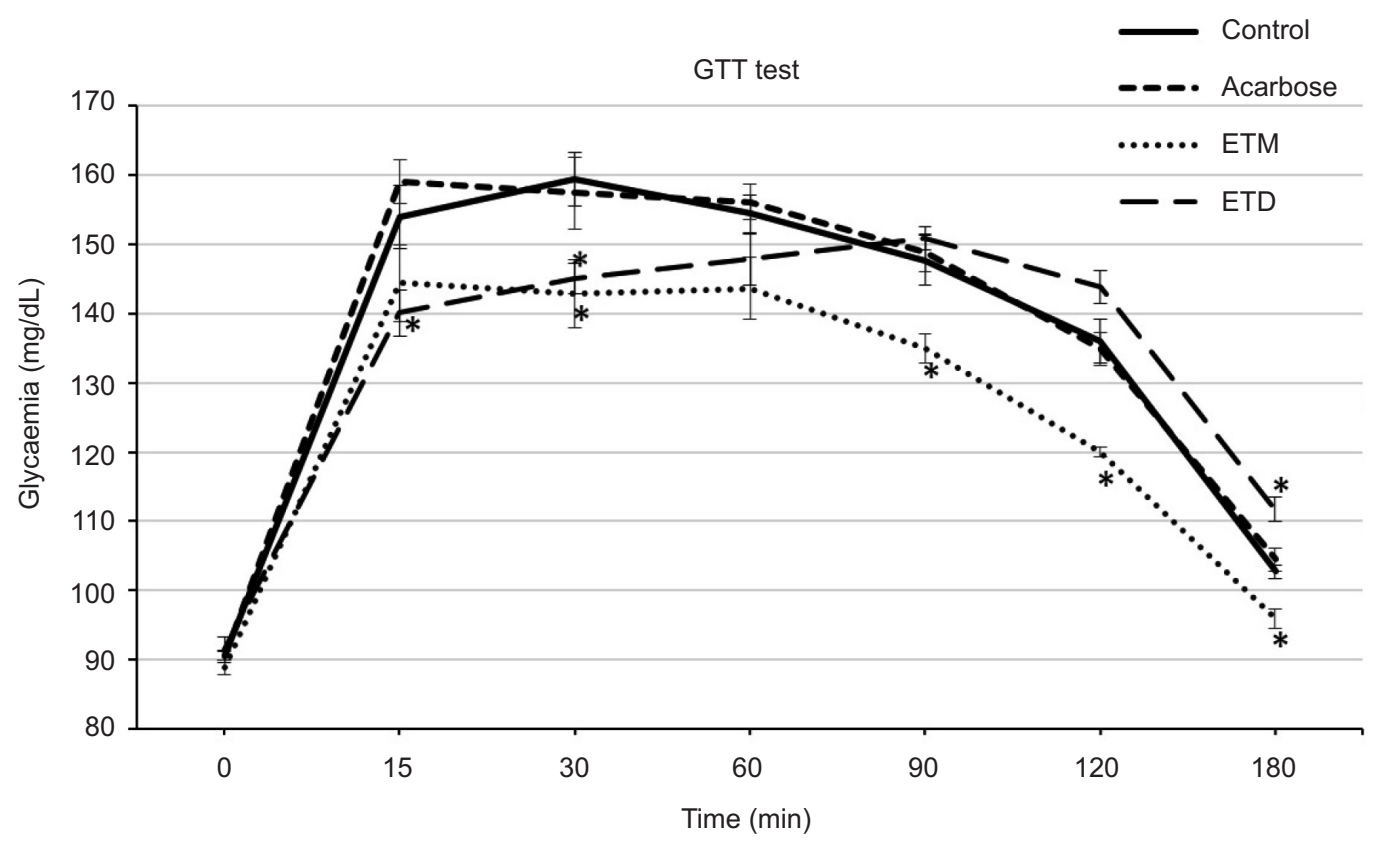

FIGURE 1. The oral glucose tolerance test (GTT) of rats. *Mean values $\pm \mathrm{SD}(\mathrm{n}=10)$ marked with asterisks are significantly different from the control (C) group $(P<0.05$ vs C; $t$-Student test). C, control gavaged with water; A, positive control gavaged with acarbose ( $35 \mathrm{mg} / \mathrm{kg} \mathrm{BW})$; ETM, experimental gavaged with strawberry extract rich in monomeric ellagitannins $(20 \mathrm{mg} / \mathrm{kg} \mathrm{BW})$; ETD, experimental gavaged with strawberry extract rich in dimeric ellagitannins $(20 \mathrm{mg} / \mathrm{kg} \mathrm{BW})$. 
only at the first measuring point (15 min). The values of AUC determined for treatment ETM and ETD did not differ significantly from that noted in group $\mathrm{C}(P=0.218$ and $P=0.372$, respectively).

In the StTT (starch) test, the acarbose treatment was associated with the strongest hypoglycaemic effects among all groups (Figure 3 ). The A rats had the lowest blood glucose levels at the following measuring points within the StTT test:
60, 90, $120 \mathrm{~min}$, and they were significantly different from those observed in the control animals $(P<0.05)$. A similar trend in the course of the StTT graph followed the experimental treatment with the ETD strawberry extract. At 60 and 120 min after starch ingestion there was a significantly lower glycaemia in rats gavaged with ETD, and at 90 min point a significant tendency towards lower glycaemia was also observed $(P=0.062)$, in comparison to the $\mathrm{C}$ group.

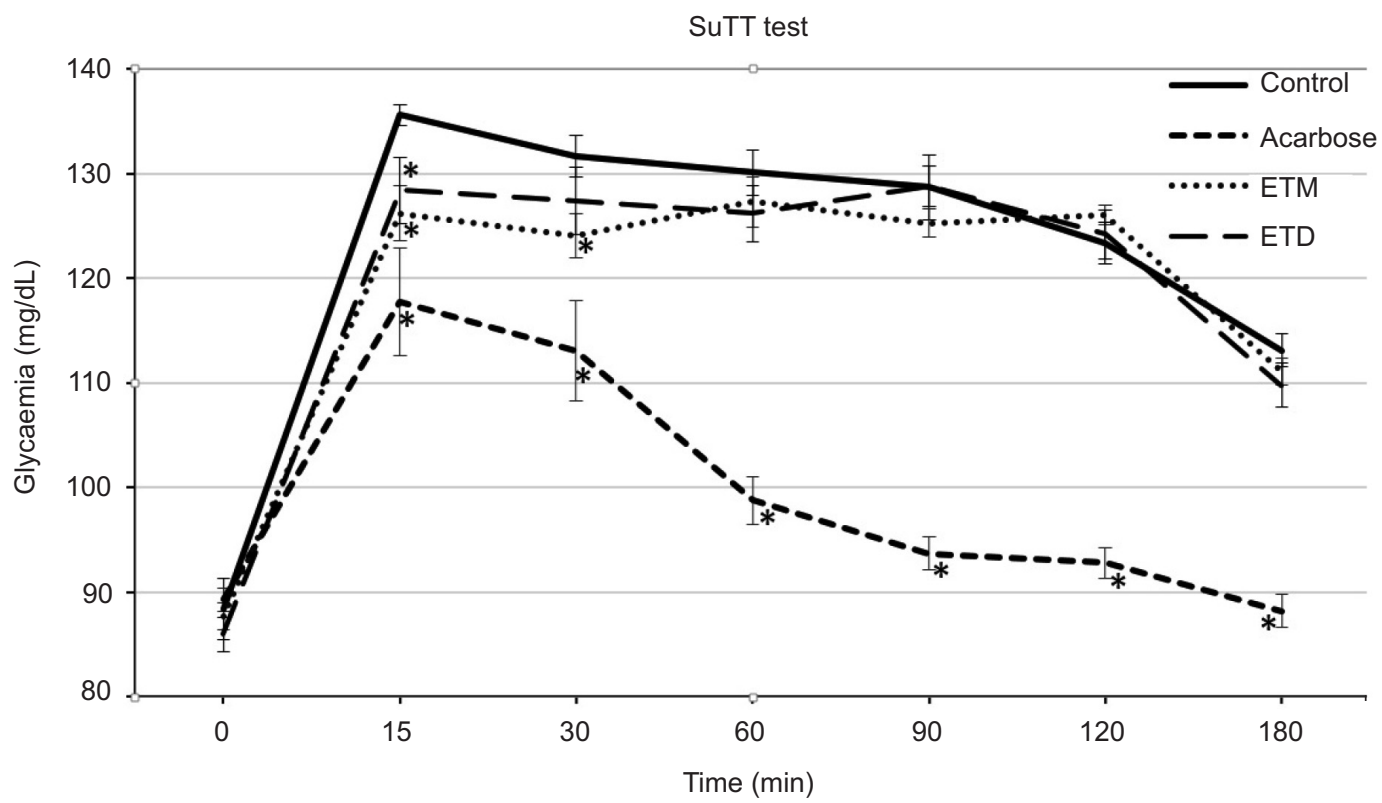

FIGURE 2. The oral sucrose tolerance test (SuTT) of rats. *Mean values $\pm \mathrm{SD}(\mathrm{n}=10)$ marked with asterisks are significantly different from the control (C) group $(P<0.05$ vs $\mathrm{C}$; $t$-Student test). C, control gavaged with water; A, positive control gavaged with acarbose $(35 \mathrm{mg} / \mathrm{kg}$ BW); ETM, experimental gavaged with strawberry extract rich in monomeric ellagitannins $(20 \mathrm{mg} / \mathrm{kg} \mathrm{BW}) ; \mathrm{ETD}$, experimental gavaged with strawberry extract rich in dimeric ellagitannins $(20 \mathrm{mg} / \mathrm{kg} \mathrm{BW})$.

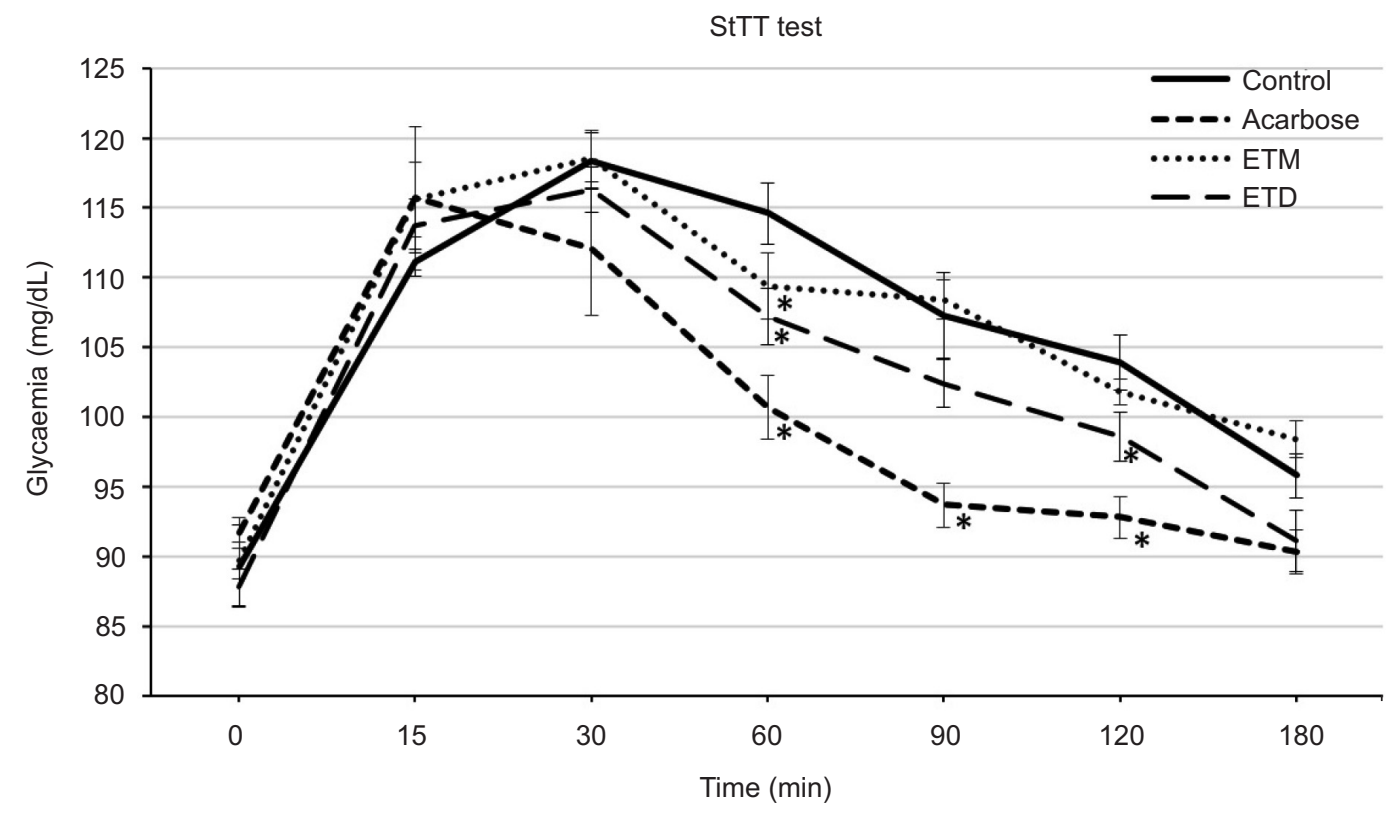

FIGURE 3. The oral starch tolerance test (StTT) of rats. *Mean values $\pm \mathrm{SD}(\mathrm{n}=10)$ marked with asterisks are significantly different from the control (C) group $(P<0.05$ vs $\mathrm{C}$; $t$-Student test). C, control gavaged with water; A, positive control gavaged with acarbose ( $35 \mathrm{mg} / \mathrm{kg} \mathrm{BW})$; ETM, experimental gavaged with strawberry extract rich in monomeric ellagitannins $(20 \mathrm{mg} / \mathrm{kg} \mathrm{BW})$; ETD, experimental gavaged with strawberry extract rich in dimeric ellagitannins $(20 \mathrm{mg} / \mathrm{kg} \mathrm{BW})$. 
As a result, the AUC value in the StTT test was statistically decreased in the A and ETD groups vs. C. The ETM rats were characterized with significantly lower glycaemia only at $60 \mathrm{~min}$ measuring point $(P<0.05 \mathrm{vs}$. control animals). The AUC value for rats TEM did not differ from that noted in group $\mathrm{C}(\mathrm{P}=0.809)$.

\section{Experiment 2}

A tendency towards lower blood glycaemia at $60 \mathrm{~min}$ measuring point was noted in rats perfused with the fluid containing glucose and strawberry ETM extract $(P=0.088$; Table 2). The absorption glucose rate during the 1-h perfusion of the small intestine as well as blood plasma glucose concentration measured after the perfusion experiment tended to be decreased in the ETM group ( $P=0.095$ and $P=0.099$, respectively). The ETM rats were also characterized with decreased activities of mucosal sucrase (statistical tendency $\mathrm{P}=0.058)$ and maltase $(P=0.032)$ in the jejunum, as it was measured immediately after the perfusion time. Neither the glycaemia within 1-h perfusion, activities of jejunal disaccharidases, nor absorption and concentration of blood plasma glucose, $\mathrm{Mg}, \mathrm{Ca}, \mathrm{P}$ were affected by the experimental addition of strawberry ETD extract to the perfusion fluid containing glucose.

In the second part of the experiment 2, the small intestine of healthy and pre-diabetic rats was perfused within $1 \mathrm{~h}$ with the fluid containing sucrose. The presence of strawberry ETM and ETD extracts did not affect significantly the glycaemia during the perfusion time (Table 3 ). The rats treated with a small dose of STZ three days before the perfusion study were characterized by significantly increased blood glucose concentrations at all measuring points $(0,15,30$ and $60 \mathrm{~min})$ and AUC value in comparison to the healthy animals (in all cases $P<0.001)$. The small intestinal absorption rate of selected minerals $(\mathrm{Ca}, \mathrm{Mg}, \mathrm{P})$ was not affected by the extract addition but it was significantly decreased by the treatment with STZ (in the case of calcium absorption, a statistical decreasing trend was observed; Table 4). Both strawberry extracts added to the perfusion fluid caused a significant reduction in the activities of sucrase and maltase measured immediately after the perfusion time in the mucosa of the jejunum. As expected, the STZ treatment was associated with considerably increased jejunal disaccharidases activity, but no significant $\mathrm{E} \times \mathrm{S}$ interaction was noted. Blood plasma glucose level, as it was measured after 1-h perfusion, was significantly decreased by the ETM but not ETD addition to the fluid (Table 5). The STZ treatment was accompanied by significantly elevated glucose $(P<0.001)$ and decreased $\mathrm{Mg}(P=0.005)$ and $\mathrm{Ca}(P=0.73)$ concentrations in the blood plasma, as compared to the healthy rats.

\section{DISCUSSION}

The ETM and ETD extracts, used in this study, contained $94.9 \%$ and $95.9 \%$ of polyphenols, respectively. The first extract contained $67 \%$ of monomeric ET, no dimeric ones, and $27.9 \%$ of proanthocyanidins. The latter extract contained $6.7 \%$ of monomeric ET, $78 \%$ of dimeric ET, and $11.2 \%$ of proanthocyanidins. Taking into account the aforementioned
TABLE 2. Glycaemia values within 1 -h perfusion of the rat small intestine with glucose-containing fluid, small intestinal absorption of glucose and selected minerals as well as activities of jejunal disaccharidases and blood serum biochemical parameters after the perfusion 1-h period.

\begin{tabular}{|c|c|c|c|c|}
\hline & $\mathrm{C}$ & ETM & ETD & $P$ \\
\hline \multicolumn{5}{|c|}{ Glycaemia (mg/dL) } \\
\hline $0 \mathrm{~min}$ & $170 \pm 5.91$ & $164 \pm 6.43$ & $162 \pm 4.50$ & 0.444 \\
\hline $15 \mathrm{~min}$ & $180 \pm 4.04$ & $172 \pm 4.72$ & $182 \pm 4.02$ & 0.254 \\
\hline $30 \mathrm{~min}$ & $189 \pm 3.72$ & $184 \pm 4.34$ & $190 \pm 3.61$ & 0.371 \\
\hline $60 \mathrm{~min}$ & $211 \pm 4.61$ & $198 \pm 5.14$ & $209 \pm 4.93$ & 0.088 \\
\hline $\begin{array}{l}\text { AUC } \\
(\mathrm{mmol} / \\
\left./ \mathrm{L}^{*} 60 \mathrm{~min}\right)\end{array}$ & $632 \pm 12.3$ & $606 \pm 14.7$ & $630 \pm 11.6$ & 0.189 \\
\hline \multicolumn{5}{|c|}{ Absorption (mg/rat/h) } \\
\hline Glucose & $105 \pm 3.44$ & $97.2 \pm 1.85$ & $104 \pm 2.90$ & 0.095 \\
\hline Magnesium & $0.387 \pm 0.025$ & $0.351 \pm 0.023$ & $0.373 \pm 0.017$ & 0.211 \\
\hline Phosphorus & $0.428 \pm 0.050$ & $0.358 \pm 0.036$ & $0.346 \pm 0.027$ & 0.254 \\
\hline Calcium & $1.02 \pm 0.105$ & $1.08 \pm 0.115$ & $1.06 \pm 0.056$ & 0.683 \\
\hline \multicolumn{5}{|c|}{ Jejunum } \\
\hline Sucrase $^{1}$ & $27.3 \pm 1.43$ & $22.0 \pm 1.83$ & $25.4 \pm 1.23$ & 0.058 \\
\hline Maltase $^{1}$ & $119 \pm 6.33^{\mathrm{a}}$ & $94.6 \pm 4.16^{b}$ & $107 \pm 4.71^{\mathrm{ab}}$ & 0.032 \\
\hline Lactase $^{1}$ & $4.17 \pm 0.311$ & $4.03 \pm 0.481$ & $4.95 \pm 0.362$ & 0.167 \\
\hline \multicolumn{5}{|c|}{ Blood serum $(\mathrm{mmol} / \mathrm{L})$} \\
\hline Magnesium & $0.790 \pm 0.020$ & $0.760 \pm 0.021$ & $0.761 \pm 0.039$ & 0.215 \\
\hline Phosphorus & $2.62 \pm 0.103$ & $2.56 \pm 0.054$ & $2.62 \pm 0.121$ & 0.696 \\
\hline Calcium & $2.19 \pm 0.086$ & $2.13 \pm 0.033$ & $2.05 \pm 0.048$ & 0.123 \\
\hline Glucose $^{1}$ & $13.1 \pm 0.18$ & $12.4 \pm 0.22$ & $12.8 \pm 0.50$ & 0.099 \\
\hline
\end{tabular}

${ }^{1} \mu \mathrm{mol} / \mathrm{min} / \mathrm{g}$ protein; AUC - area under the curve. Mean values $\pm \mathrm{SEM}$ $(\mathrm{n}=8)$ within a row marked with different letters are significantly different from each other $(P<0.05$; one-way ANOVA and Duncan test). $\mathrm{C}$, control; ETM, experimental with strawberry extract rich in monomeric ellagitannins; ETD, experimental with strawberry extract rich in dimeric ellagitannins.

chemical composition of the strawberry extracts, one can assume that changes in biological response of rats found in the present study should be mainly ascribed to the different degree of polymerization (DP) of ellagitannins. In fact, that difference in DP of ET between two extracts was quite small, but the results obtained clearly showed that monomeric and dimeric ellagitannins may, when ingested, act differently on physiological mechanisms leading to glycaemic response of the host. Considering the shape of blood glucose concentration curve following the oral GTT and the perfusion experiment with glucose-containing fluid, the monomeric ET (vs. dimeric) more positively mitigated sugar-induced postprandial glycaemic load. It is important to note that the lowering effect of ETM on blood glycaemia extract was also confirmed by a significantly lower AUC value in comparison to the $\mathrm{C}$ group. The hypoglycaemic effect of strawberry dimeric ET from ETD extract was similarly, or even more, effective within 
TABLE 3. Glycaemia values within $1-h$ perfusion of the rat small intestine with sucrose-containing fluid.

\begin{tabular}{|c|c|c|c|c|c|}
\hline & $0 \mathrm{~min}$ & $15 \mathrm{~min}$ & $30 \mathrm{~min}$ & $60 \mathrm{~min}$ & AUC* \\
\hline & $\mathrm{mg} / \mathrm{dL}$ & $\mathrm{mg} / \mathrm{dL}$ & $\mathrm{mg} / \mathrm{dL}$ & $\mathrm{mg} / \mathrm{dL}$ & $\begin{array}{l}\mathrm{mmol} / \mathrm{L} \\
* 60 \mathrm{~min}\end{array}$ \\
\hline $\mathrm{C}$ & 155 & 163 & 172 & 179 & 564 \\
\hline $\begin{array}{l}\mathrm{C} \\
+\mathrm{STZ}\end{array}$ & 190 & 195 & 199 & 200 & 657 \\
\hline ETM & 154 & 158 & 163 & 168 & 539 \\
\hline $\begin{array}{l}\text { ETM } \\
+ \text { STZ }\end{array}$ & 187 & 188 & 194 & 195 & 638 \\
\hline ETD & 152 & 156 & 165 & 172 & 542 \\
\hline $\begin{array}{l}\text { ETD } \\
+ \text { STZ }\end{array}$ & 185 & 190 & 195 & 204 & 648 \\
\hline SEM & 3.161 & 3.297 & 3.099 & 2.987 & 10.19 \\
\hline \multicolumn{6}{|c|}{ Extract $(\mathrm{E})$} \\
\hline- & 172 & 179 & 186 & 190 & 610 \\
\hline ETM & 171 & 173 & 179 & 182 & 589 \\
\hline ETD & 168 & 173 & 180 & 188 & 595 \\
\hline Pvalue & 0.767 & 0.531 & 0.412 & 0.325 & 0.489 \\
\hline \multicolumn{6}{|c|}{ STZ (S) } \\
\hline- & $154^{\mathrm{b}}$ & $159^{b}$ & $167^{\mathrm{b}}$ & $173^{\mathrm{b}}$ & $548^{\mathrm{b}}$ \\
\hline+ & $187^{\mathrm{a}}$ & $191^{\mathrm{a}}$ & $196^{\mathrm{a}}$ & $200^{\mathrm{a}}$ & $648^{\mathrm{a}}$ \\
\hline Pvalue & $<0.001$ & $<0.001$ & $<0.001$ & $<0.001$ & $<0.001$ \\
\hline \multicolumn{6}{|c|}{ Interaction $\mathrm{E} \times \mathrm{S}$} \\
\hline Pvalue & 0.972 & 0.940 & 0.966 & 0.654 & 0.941 \\
\hline
\end{tabular}

*AUC - area under the curve $\left(\mathrm{mmol} / \mathrm{L}^{*} 60 \mathrm{~min}\right)$. Mean values and pooled SEM $(n=48)$ marked within a column with different letters are significantly different from each other $(P<0.05$; two-way ANOVA and in the case of significant interaction $\mathrm{E} \times \mathrm{S}$ the Duncan test was applied). C, control; ETM, experimental with strawberry extract rich in monomeric ellagitannins; ETD, experimental with strawberry extract rich in dimeric ellagitannins; STZ - rats treated with streptozotocin intraperitoneal injection $(20 \mathrm{mg} / \mathrm{kg} \mathrm{BW})$ three days before the perfusion experiment.

the first 30 min of GTT test - which seems to be of paramount importance when the control of postprandial blood glucose level must be quick leading to the flattening of the first glucose peak after meal. The AUC value for extract ETD did not differ from that noted in the control animals because within the second and third hour of the GTT test that extract was less or even ineffective as hypoglycaemic agent. It should be also emphasized that at the termination of the perfusion experiment, blood samples were taken and serum was obtained. In the serum, the presence of ET metabolites was analyzed using HPLC-ESI-MS method. Both, in rats perfused with the fluid containing glucose and in those treated with sucrose-containing fluid, no metabolites in the blood serum have been found. This confirmed earlier findings that due to a large molecular size of ET, these compounds are not absorbed in the upper intestine but reach the large gut where ET are metabolized by microbiota [Fotschki et al., 2014]. Glu-
TABLE 4. Small intestinal absorption of selected minerals during 1-h perfusion of the rat small intestine with sucrose-containing fluid as well as activities of jejunal disaccharidases and blood serum biochemical parameters after the perfusion 1-h period.

\begin{tabular}{|c|c|c|c|c|c|c|}
\hline & $\mathrm{Mg}$ & $\mathrm{P}$ & $\mathrm{Ca}$ & Sucrase & Maltase & Lactase \\
\hline & \multicolumn{3}{|c|}{$\mathrm{mg} / \mathrm{rat} / \mathrm{h}$} & \multicolumn{3}{|c|}{$\mu \mathrm{mol} / \mathrm{min} / \mathrm{g}$ protein } \\
\hline $\mathrm{C}$ & 0.366 & 0.369 & 0.906 & 32.6 & 100 & 4.28 \\
\hline $\begin{array}{l}\mathrm{C} \\
+\mathrm{STZ}\end{array}$ & 0.149 & 0.287 & 0.852 & 40.6 & 111 & 5.13 \\
\hline ETM & 0.312 & 0.348 & 0.966 & 25.0 & 85.8 & 4.08 \\
\hline $\begin{array}{l}\text { ETM } \\
+ \text { STZ }\end{array}$ & 0.172 & 0.292 & 0.898 & 30.4 & 103 & 4.63 \\
\hline ETD & 0.310 & 0.345 & 0.987 & 29.5 & 92.8 & 4.40 \\
\hline $\begin{array}{l}\text { ETD } \\
+ \text { STZ }\end{array}$ & 0.175 & 0.268 & 0.849 & 35.0 & 98.6 & 5.00 \\
\hline SEM & 0.015 & 0.012 & 0.023 & 0.944 & 1.858 & 0.129 \\
\hline \multicolumn{7}{|c|}{ Extract $(\mathrm{E})$} \\
\hline- & 0.258 & 0.328 & 0.879 & $36.4^{\mathrm{a}}$ & $105^{\mathrm{a}}$ & 4.70 \\
\hline ETM & 0.242 & 0.320 & 0.932 & $27.7^{\mathrm{c}}$ & $94.2^{\mathrm{b}}$ & 4.35 \\
\hline ETD & 0.242 & 0.306 & 0.918 & $32.3^{\mathrm{b}}$ & $95.6^{\mathrm{b}}$ & 4.70 \\
\hline Pvalue & 0.659 & 0.745 & 0.625 & $<0.001$ & 0.010 & 0.426 \\
\hline \multicolumn{7}{|c|}{ STZ (S) } \\
\hline- & $0.329^{\mathrm{a}}$ & $0.354^{\mathrm{a}}$ & 0.953 & $29.0^{\mathrm{b}}$ & $92.9^{\mathrm{b}}$ & $4.25^{\mathrm{b}}$ \\
\hline+ & $0.165^{\mathrm{b}}$ & $0.282^{\mathrm{b}}$ & 0.866 & $35.3^{\mathrm{a}}$ & $107^{\mathrm{a}}$ & $4.92^{\mathrm{a}}$ \\
\hline Pvalue & $<0.001$ & 0.004 & 0.067 & $<0.001$ & 0.001 & 0.010 \\
\hline \multicolumn{7}{|c|}{ Interaction $\mathrm{E} \times \mathrm{S}$} \\
\hline Pvalue & 0.081 & 0.891 & 0.730 & 0.739 & 0.351 & 0.871 \\
\hline
\end{tabular}

Mean values and pooled SEM $(n=48)$ marked within a column with different letters are significantly different from each other $(P<0.05$; twoway ANOVA and in the case of significant interaction $\mathrm{E} \times \mathrm{S}$ the Duncan test was applied). C, control; ETM, experimental with strawberry extract rich in monomeric ellagitannins; ETD, experimental with strawberry extract rich in dimeric ellagitannins; STZ - rats treated with streptozotocin intraperitoneal injection ( $20 \mathrm{mg} / \mathrm{kg} \mathrm{BW}$ ) three days before the perfusion experiment.

cose, as a very hydrophilic monosaccharide, cannot cross biological membranes unaided, and it is absorbed and then taken to the tissues by transporters, mainly GLUT2 and SGLT1 [Scheepers et al., 2004]. GLUT2 is responsible for glucose absorption in the gut especially at high glucose concentration as it is rapidly moved to the apical side of enterocytes within a few minutes after meal [Williamson, 2013]. SGLT1 is a classical $\mathrm{Na}^{+}$/glucose cotransporter which also regulates the release of key hormones (glucose-dependent insulinotropic polypeptide and glucagon-like peptide-1) affecting the glycaemic response from enteroendocrine cells in the intestinal epithelium [Wu et al., 2010]. Considering the accepted hypothesis of the present study, it seems that the inhibiting effect of the ETD extract on glucose transport across the intestine, probably via GLUT2 and SGLT1, was short-time and not prolonged as it was observed in the case of the ETM extract. To the best of our knowledge, there are no reports about el- 
TABLE 5. Blood serum biochemical parameters of rats after the perfusion 1-h period with the sucrose-containing fluid $(\mathrm{mmol} / \mathrm{L})$.

\begin{tabular}{|c|c|c|c|c|}
\hline & 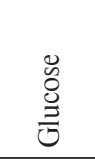 & 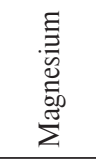 & 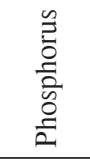 & $\frac{\Xi}{\Xi_{0}^{0}}$ \\
\hline $\mathrm{C}$ & 11.9 & 0.718 & 2.32 & 1.98 \\
\hline $\mathrm{C}+\mathrm{STZ}$ & 14.5 & 0.620 & 2.25 & 1.89 \\
\hline ETM & 11.0 & 0.700 & 2.37 & 1.96 \\
\hline $\mathrm{ETM}+\mathrm{STZ}$ & 12.4 & 0.646 & 2.35 & 1.91 \\
\hline ETD & 11.5 & 0.710 & 2.43 & 2.10 \\
\hline $\mathrm{ETD}+\mathrm{STZ}$ & 14.4 & 0.653 & 2.14 & 1.92 \\
\hline SEM & 0.290 & 0.012 & 0.041 & 0.029 \\
\hline \multicolumn{5}{|c|}{ Extract (E) } \\
\hline- & $13.2^{\mathrm{a}}$ & 0.669 & 2.28 & 1.94 \\
\hline ETM & $11.7^{\mathrm{b}}$ & 0.673 & 2.36 & 1.93 \\
\hline ETD & $13.0^{\mathrm{a}}$ & 0.681 & 2.28 & 2.01 \\
\hline Pvalue & 0.017 & 0.906 & 0.673 & 0.489 \\
\hline \multicolumn{5}{|c|}{ STZ (S) } \\
\hline- & $11.5^{\mathrm{b}}$ & $0.709^{\mathrm{a}}$ & 2.37 & 2.01 \\
\hline+ & $13.8^{\mathrm{a}}$ & $0.639^{\mathrm{b}}$ & 2.25 & 1.91 \\
\hline Pvalue & $<0.001$ & 0.005 & 0.132 & 0.073 \\
\hline \multicolumn{5}{|c|}{ Interaction $\mathrm{E} \times \mathrm{S}$} \\
\hline Pvalue & 0.364 & 0.704 & 0.373 & 0.677 \\
\hline
\end{tabular}

Mean values and pooled SEM $(n=48)$ marked within a column with different letters are significantly different from each other $(P<0.05$; two-way ANOVA and in the case of significant interaction $\mathrm{E} \times \mathrm{S}$ the Duncan test was applied). C, control; ETM, experimental with strawberry extract rich in monomeric ellagitannins; ETD, experimental with strawberry extract rich in dimeric ellagitannins; STZ - rats treated with streptozotocin intraperitoneal injection $(20 \mathrm{mg} / \mathrm{kg} \mathrm{BW})$ three days before the perfusion experiment.

lagitannins and related GLUT2/SGLT1 inhibition. Some authors have only shown that a strawberry extract was able to inhibit the apical to basolateral transfer of glucose in vitro using Caco-2 cells [Manzano \& Williamson, 2010].

The main dietary sources of glucose are starch and sucrose, both of which must be digested before the component monosaccharides could be absorbed from the intestinal lumen [Williamson, 2013]. The oral sucrose tolerance test (SuTT) as well as the changes in some biochemical indices (sucrase mucosal activity, blood glucose level) measured after the 1-h perfusion of rat small intestine with fluid containing sucrose led to the conclusion that again the monomeric ET-rich extract displayed a greater hypoglycaemic potential in comparison to the ETD extract. That effect seems to be a coupled inhibiting action of the ETM extract on mucosal disaccharidases activity and then glucose transport across the intestine wall. Maltase-glucoamylase (EC 3.2.1.20 also called maltase/ $\alpha$-glucosidase) and sucrase-isomaltase (EC 3.2.1.48) are both attached to the brush border membrane of entero- cytes and act on substrates in the gut lumen, although, unlike $\alpha$-amylase (starch digestion) are not secreted [Sim et al., 2010]. Indeed, both perfusion experiments with glucose- or sucrose-containing fluids revealed more potent inhibiting action of the ETM extract (vs. ETD one) on the activities of mucosal sucrase and maltase. The perfusion experiment using the sucrose-containing fluid was conducted, in part, on pre-diabetic rats treated with $20 \mathrm{mg} / \mathrm{kg} \mathrm{BW}$ of streptozotocin three days before that experiment. It has been postulated that increased levels of disaccharidases activity in diabetic state resulted from the lack of insulin which has an inhibitory effect on these enzymes activity [Juśkiewicz et al., 2008b]. Contrary to expectations, both strawberry extracts used in the present study did not mitigate disorders caused by STZ injection.

In the present study, the dimeric ET-rich extract, potently mitigated starch-induced postprandial glycaemic load. This may lead to an inhibition effect of that extract on pancreatic $\alpha$-amylase activity. $\alpha$-Amylase (EC 3.2.1.1) hydrolyzes the $\alpha-1,4$-glycosidic bonds in both amylose and amylopectin, but cannot hydrolyze the $\alpha$-1,6-glycosidic bonds which form the branch points [Williamson, 2013]. It has been reported that berry polyphenols, especially raspberry, rowanberry and blueberry, inhibit pig pancreatic $\alpha$-amylase with one of the active components proposed to be proanthocyanidins [Bacon \& Rhodes, 2000]. In this case, strawberry polyphenolic extracts showed lower activity against pancreatic $\alpha$-amylase [Bacon \& Rhodes, 2000; da Silva et al., 2008]. In the present study, the main part of the observed hypoglycaemic action of strawberry polyphenols in the oral StTT test should be ascribed to other than proanthocyanidin components which means dimeric ellagitannins. In fact, both examined extracts ETM and ETD contained considerable amounts of proanthocyanidins, but the ETM one - which was characterized by similar glycaemia to control during the StTT - contained two and half more of these polyphenols than the ETD extract.

To sum up, the results of the present study showed that the separate mechanisms (glucose transport, intestinal mucosal disaccharidases inhibition activity, pancreatic $\alpha$-amylase inhibitory activity) leading to decreased postprandial glycaemia upon dietary administration of strawberry ellagitannins largely depended on their chemical structure, i.e. degree of polymerization. It seems that monomeric ET (vs. dimeric) more positively mitigated glucose- or sucrose-induced postprandial glycaemic load. The dimeric ET, in turn, potently mitigated starch-induced postprandial glycaemia.

\section{ACKNOWLEDGEMENTS}

The study was supported by the National Science Centre Poland (grant DEC-2012/05/B/NZ9/03402).

\section{REFERENCES}

1. AOAC. Official Methods of Analysis of AOAC International. $18^{\text {th }}$ Edition. Editor Horowitz. W. Latimer. G.W. AOAC International, 2005, Maryland. USA.

2. Bacon J.R., Rhodes M.J., Binding affinity of hydrolysable tannins to parotid saliva and to proline-rich proteins derived from it. J. Agric. Food Chem., 2000, 48, 838-843. 
3. Espin J.C., Garcia-Conesa M.T., Tomas-Barberan F.A., Nutraceuticals: Facts and fiction. Phytochemistry, 2007, 68, 2986-3008.

4. Fotschki B., Milala J., Jurgoński A., Karlińska E., Zduńczyk Z., Juśkiewicz J., Strawberry ellagitannins thwarted the positive effects of dietary fructooligosaccharides in rat cecum. J. Agric. Food Chem., 2014, 62, 5871-5880.

5. Jurgoński A., Juśkiewicz J., Zduńczyk Z., An anthocyanin-rich extract from Kamchatka honeysuckle increases enzymatic activity within the gut and ameliorates abnormal lipid and glucose metabolism in rats. Nutrition, 2013, 29, 898-902.

6. Jurgoński A., Krotkiewski M., Juśkiewicz J., Billing-Marczak K., Suppression of postprandial glycaemia by L-arabinose in rats is more associated with starch than sucrose ingestion - short-report. Pol. J. Food Nutr. Sci., 2015, 65, 57-60.

7. Juśkiewicz, J., Zduńczyk Z., Jankowski J., Król B., Milala J., Gastrointestinal tract metabolism of young turkeys fed diets supplemented with pure nystose or a fructooligosaccharide mixture. Arch. Anim. Nutr., 2008a, 62, 389-403.

8. Juśkiewicz, J., Zduńczyk Z., Jurgoński A., Brzuzan Ł., GodyckaKłos I., Żary-Sikorska E., Extract of green tea leaves partially attenuates streptozotocin-induced changes in antioxidant status and gastrointestinal functioning in rats. Nutr. Res., 2008b, 28, 343-349.

9. Juśkiewicz, J., Zduńczyk Z., Król B., Jankowski J., Mikulski D., Jurgoński A., Influence of chicory preparation containing fructans and polyphenols on nitrogen excretion patterns and ileal mineral absorption in rats. Vet. Med. Zoot., 2009, 47, 10-15.

10. Juśkiewicz J., Król B., Kosmala M., Milala J., Zduńczyk Z., ŻarySikorska E., Physiological properties of dietary ellagitannins-rich preparations obtained from strawberry pomace using different extraction methods. Pol. J. Food Nutr. Sci., 2015, 65, 199-209.

11. Kennedy J.A., Jones G.P., Analysis of proanthocyanidins cleavage products following acid-catalysis in the presence of excess phloroglucinol. J. Agric. Food Chem., 2001, 49, 1740-1746.

12. Kosmala M., Zduńczyk Z., Juśkiewicz J., Jurgoński A., Karlińska E., Macierzyński J., Jańczak R., Rój E., Chemical composition of defatted strawberry and raspberry seeds and the effect of these dietary ingredients on polyphenol metabolites, intestinal function, and selected serum parameters in rats. J. Agric. Food Chem., 2015, 63, 2989-2996.

13. Manzano S., Williamson G., Polyphenols and phenolic acids from strawberry and apple decrease glucose uptake and transport by human intestinal Caco-2 cells. Mol. Nutr. Food Res., 2010, 54, 1773-1780.

14. Saris W.H.M., Asp N.G.L., Björck I., Blaak E., Bornet F., Brouns F., Frayn K.N., Fürst P., Riccardi G., Roberfroid M., Vogel M., Functional food science and substrate metabolism. Brit. J. Nutr., 1998, 80, Suppl., 1, S47-S75.

15. Scheepers A., Joost H.G., Schurmann A., The glucose transporter families SGLT and GLUT: molecular basis of normal and aberrant function. J. Pareneter. Enteral Nutr., 2004, 28, 364-371.

16. da Silva P.M., Kwon Y.I., Apostolidis E., Lajolo F.M., Genovese M.I., Shetty K., Functionality of bioactive compounds in Brazilian strawberry (Fragaria $\times$ ananassa Duch.) cultivars: evaluation of hyperglycemia and hypertension potential using in vitro models. J. Agric. Food Chem., 2008, 56, 4386-4392.

17. Sim L., Willemsma C., Mohan S., Naim H.Y., Pinto B.M., Rose D.R., Structural basis for substrate selectivity in human maltase-glucoamylase and sucrase-isomaltase $\mathrm{N}$-terminal domains. J. Biol. Chem., 2010, 285, 17763-17770.

18. Sójka M., Klimczak E., Macierzyński J., Kołodziejczyk K., Nutrient and polyphenolic composition of industrial strawberry press cake. Eur. Food Res. Technol., 2013, 237, 995-1007.

19. Williamson G., Possible effects of dietary polyphenols on sugar absorption and digestion. Mol. Nutr. Food Res., 2013, 57, 48-57.

20. Wu T., Rayner C.K., Jones K., Horowitz M., Dietary effects on incretin hormone secretion. Vitam. Horm., 2010, 84, 81-110.

21. Zduńczyk Z., Juśkiewicz J., Frejnagel S., Gulewicz K., Influence of alkaloids and oligosaccharides from white lupin seeds on utilization of diets by rats and absorption of nutrients in the small intestine. Anim. Feed Sci. Technol., 1998, 72, 143-154.

Submitted: 16 September 2015. Revised: 31 December 2015. Accepted 27 January 2016. Published on-line: 11 March 2016. 
